\title{
NOTAS SOBRE LA VOZ LLETA EN LOS DICCIONARIOS ACADÉMICOS Y EN LOS ATLAS LINGÜISTICOS
}

\author{
ANA IsABEl NAVARRo CARRASCO \\ (Universidad de Alicante)
}

El 'aguijón que echan las plantas cuando comienzan a nacer' recibe la denominación de lleta en la mitad oriental de Andalucía según los datos que nos ofrece el $A L E A^{1}$, así como en la provincia de Teruel y sur de Zaragoza según nos dice el $A L E A N R^{2}$ y, sin embargo, la última edición del Diccionario Académico ${ }^{3}$ no recoge la voz, tampoco la penúltima de $1984^{4}$ ni la antepenúltima de $1970^{5}$, aunque sí aparece en la anterior, en la decimoctava de $1956^{6}$ y en las anteriores. Entonces, surge la pregunta ¿por qué se ha suprimido una voz vigente en nuestra geografía?

En estas páginas pretendemos hacer un recorrido por los Diccionarios Académicos para comprobar cuándo se incorporó la voz a la compilación oficial, cuáles son las ediciones en las que aparece y cuáles no. Por otro lado, veremos a través de los atlas lingüísticos la distribución de lleta sobre la geografía

1 M. Alvar con la colaboración de A. Llorente y G. Salvador, Atlas lingüístico y etnográfico de Andalucia, Granada, Universidad-CSIC, 1961-1973, 6 tomos: tomo I, mapa 31.

2 M. Alvar con la colaboración de A. Llorente, T. Buesa y E. Alvar, Atlas lingüístico y etnográfico de Aragón, Navarra y Rioja, Zaragoza, Departamento de Geografía lingüística, Instituto Fernando El Católico de la Excma. Diputación, CSIC, 1979-1983, 12 tomos: I, 49. $21^{\mathrm{a}} \mathrm{ed}$.

3 Real Academia Española, Diccionario de la lengua española, Madrid, Espasa-Calpe, 1992,

4 Real Academia Española, Diccionario de la lengua española, Madrid, Espasa-Calpe, 1984, 20 ed., 2 tomos.

5 Real Academia Española, Diccionario de la lengua española, Madrid, Espasa-Calpe, 1970, $19^{\mathrm{a}} \mathrm{ed}$.

- Real Academia Española, Diccionario de la lengua española, Madrid, Espasa-Calpe, 1956, $18^{\mathrm{a}} \mathrm{ed}$. 


\section{peninsular.}

La primera vez que encontramos el término lleta en el Diccionario Académico es en la $4^{\mathrm{a}}$ edición de $1803^{7}$ y se define como

el tallo recién nacido de las plantas que producen las semillas y cebollas, Scapus caulis .

No figura en el Diccionario de Autoridades $(1726)^{9}$, ni en la $1^{\underline{a}}$ edición de $1780^{10}$, ni en la $2^{\underline{a}}$ de $1783^{11}$, ni en la $3^{\underline{a}}$ de $1791^{12}$. A partir de la cuarta edición seguirá apareciendo con la misma definición en la $5^{\mathrm{a}}$ del año $1817^{13}$, en la $6^{\mathrm{a}}$ de $1822^{14}$, en la $7^{\mathrm{a}}$ de $1832^{15}$, en la $8^{\mathrm{a}}$ de $1837^{16}$, en la $9^{\mathrm{a}}$ de $1843^{17}$, en la $10^{\mathrm{a}}$ de $1852^{18}$, en la $11^{\underline{a}}$ de $1869^{19}$ —omitiéndose a partir de ahora el equivalente latino Scapus caulis-.

En la $12^{-a}$ edición de $1884^{20}$ la definición se remodela y se dice que es

tallo recién nacido ó del bulbo de una planta ${ }^{21}$.

" Real Academia Española, Diccionario de la lengua castellana, Madrid, Viuda de Don Joaquín Ibarra, 1803, $4^{\mathrm{a}}$ ed.

I Ibidem, s.v.

9 Real Academia Española, Diccionario de la lengua castellana, Madrid, Imprenta de Francisco del Hierro, 1726. Manejo la edición facsímil, Madrid, Gredos, 1979, 3 tomos, reimpresión.

10 Real Academia Española, Diccionario de la lengua castellana reducido a un tomo para su más fácil uso. Facsímil de la primera edición (1780). Introducción de Manuel Seco. Madrid, Imprenta Aguirre, 1991.

11 Real Academia Española, Diccionario de la lengua castellana, Madrid, D. Joaquín Ibarra, $178 \hat{3}, 2^{2} \mathrm{ed}$.

12 Real Academia Española, Diccionario de la lengua castellana, Madrid, Viuda de don Joaquín Ibarra, 1791, $3^{\frac{a}{}}$ ed.

13 Real Academia Española, Diccionario de la lengua castellana, Madrid, Imprenta Real, 1817, $5^{\text {a }}$ ed.

14 Academia Española, Diccionario de la lengua castellana, Madrid, Imprenta Nacional, 1822, $6^{\mathrm{a}}$ ed.

15 Academia Española, Diccionario de la lengua castellana, Madrid, Imprenta Real, 1832, $7^{\text {a }}$ ed.

16 Academia Española, Diccionario de la lengua castellana, Madrid, Imprenta Nacional, 1837, $8^{\mathrm{a}}$ ed.

17 Academia Española, Diccionario de la lengua castellana, Madrid, Imprenta de D. Francisco María Fernández, 1843, 9ª ed.

18 Academia Española, Diccionario de la lengua castellana, Madrid, Imprenta Nacional, 1852, $10^{\mathrm{x}} \mathrm{ed}$.

19 Real Academia Española, Diccionario de la lengua castellana, Madrid, Imprenta de Don Manuel Rivadeneyra, 1869, $11^{\underline{\mathbf{a}}} \mathrm{ed}$.

20 Real Academia Española, Diccionario de la lengua castellana, Madrid, Imprenta de D. Gregorio Hernando, 1884, 12ª ed.

21 Ibidem, s. v. lleta 
Lo mismo se dice en la $13^{\underline{a}}$ edición de $1899^{22}$, en la $14^{\mathrm{a}}$ de 1914 -donde se le quita la tilde a la $o-^{23}$, en la $15^{\mathrm{a}}$ de $1925^{24}$, en la $16^{\mathrm{a}}$ de $1939^{25}$, en la $17^{\mathrm{a}}$ de $1947^{26}$ y en la $18^{\mathrm{a}}$ de $1956^{27}$. Y, a partir de ahora - como hemos dicho anteriormente-, ya no aparecerá en la $19^{\underline{a}}$ de $1970^{28}$, ni en la $20^{\underline{a}}$ de $1984^{29}$, ni en la $21^{\underline{a}}$ de $1992^{30}$. De manera que a partir de 1970 la Academia omitió la voz lleta de las páginas de su Diccionario. ¿Qué dicen los atlas lingüísticos al respecto? Es sabido -y lo hemos repetido muchas veces - ${ }^{31}$ que la lexicografía no se ocupa de dar cabida a las voces de los atlas lingüísticos.

En el $A L E A^{32}$ la distribución de la voz lleta aparece de manera generalizada en las provincias de Almería, Granada, Jaén y este de Córdoba formando una área compacta que, además, sirve para caracterizar la mitad oriental de Andalucía ${ }^{33}$.

En el ALEANR ${ }^{34}$ aparece lleta ${ }^{35}$ en Teruel, suroeste de Zaragoza y los puntos de Soria, Guadalajara, Cuenca y Valencia que dicho Atlas recoge ${ }^{36}$.

22 Real Academia Española, Diccionario de la lengua castellana, Madrid, Imprenta de los Sres. Hernando y Compañía, 1899, $13^{\mathrm{a}}$ ed.

23 Real Academia Española, Diccionario de la lengua castellana, Madrid, Imprenta de los Sucesores de Hernando, 1914, 14ª ed.

24 Real Academia Española, Diccionario de la lengua española, Madrid, Talleres Calpe, 1925 , $15^{\mathrm{x}} \mathrm{ed}$.

25 Real Academia Española, Diccionario de la lengua española, Madrid, Espasa-Calpe, 1939, $16^{\mathrm{a}} \mathrm{ed}$.

26 Real Academia Española, Diccionario de la lengua española, Madrid, Espasa-Calpe, 1947 , $17^{\mathrm{a}} \mathrm{ed}$.

27 Real Academia Española, Diccionario de la lengua española, Madrid, Espasa-Calpe, 1956, $18^{2} \mathrm{ed}$.

28 Op.cit.

29 Op. cit.

30 Op. cit.

31 «Voces del Atlas lingǘstico y etnográfico de Andalucía no recogidas por el Diccionario Académico $\left(1984,20^{\mathrm{a}}\right.$ ed.)», Español Actual, 54 (1990), págs. 41-90; «Términos del tomo I del ALEICan que no figuran en el Diccionario de la Real Academia Española (1984, 20 ed.)», en M. Ariza, R. Cano, J. M Mendoza, A. Narbona (editores), Actas del II Congreso Internacional de Historia de la Lengua Española, Madrid, Pabellón de España, 1992, 2 tomos: tomo I, págs. 1251 1265; «Geografía lingüística y diccionarios», en Estudios de Lingǘstica, 9 (1993), págs. 73-96.

32. Op. cit.

${ }_{33} \mathrm{Al} 100,200,201,203,204,300,301,302,303,400,401,403,404,405,500,501,503,504$, $505,506,509,600,601,602$; Gr 200, 201, 202, 203, 300, 301, 302, 304, 305, 306, 400, 401, 402, $403,404,405,406,407,409,410,500,501,502,503,504,505,508,509,511,513,515,600,601$, $602,603,604 ; \mathrm{J} 100,101,102,103$ (lletilla, lleta), 200, 202, 204, 300, 302, 303, 304, 306, 307, 308, $309,400,401,402,403,404,500,502,503,600$; Co 200, 201, 202, 400, 403.

34 Op. cit.

35 I, 49

36 Concretamente lleta aparece en Te 103, 301, 302, 303, 304, 305, 306, 307, 501, 502, 504; Z 500, 505, 506, 507 (lieta); So 600; Gu 200, 400; Cu 200, 400; V 100, 101. 
En el Atlas Lingüístico y Etnográfico de las Islas Canarias, ALEICan ${ }^{37}$, no aparece el mapa de la «Lleta». No poseemos datos del aún inédito Atlas Ling üístico y Etnográfico de Santander, el ALES, pero sabemos que incluye este mapa ${ }^{38}$ por la indicación que nos hace $\mathrm{M}^{\mathbf{a}} \mathrm{A}$. Luzón en los Indices léxicos de los atlas lingülísticos españoles ${ }^{39}$.

Hay que hacer una observación. En los atlas mencionados la pregunta es la siguiente: ¿Cómo se llama la agujita que echa el trigo cuando nace? Es decir, se pregunta por el 'cereal que asoma' y la definición de los diccionarios es más amplia. En cualquier caso se trata del brote de vegetales.

J. Fernández-Sevilla ${ }^{40}$ nos decía respecto a este término:

La voz lleta está poco extendida en las zonas de habla castellana y no parece que sea frecuente en otras regiones de la Península. Tanto es así que el $D R A E$ en su última edición [se refiere a la $19^{2}$ de 1970 ] ha decidido suprimirlo. Para adoptar tal medida no ha sido tenida en cuenta, sin duda, su vitalidad en Andalucía ${ }^{41}$.

Y siempre surge la misma pregunta: ¿qué criterios se siguen para incluir o excluir - - en este caso - unas voces sí y otras no en los diccionarios? La lexicografía, desde muchos puntos de vista, debería ser más rigurosa.

Alcalá Venceslada no recoge lleta en su Vocabulario Andaluz ${ }^{42}$. En relación a esto Fernández-Sevilla nos dice:

es probable que ello se deba a que cuando éste preparaba su Vocabulario la palabra aparecía incluida en el $D R A E$ y, por tanto, no creyó necesaria «recogerla» ${ }^{43}$.

En cuanto a la etimología, Corominas ${ }^{44}$ cree que el término, aunque de origen incierto, quizá esté tomado del francés antiguo jette 'retoño' por conducto de una forma gascona *yete. Ahora bien, dice el etimólogo, si el vocablo es usual en regiones donde no haya habido jamás confusiones de $l l$ e $y$, ni paso de $L$ - a $l l$ (León) el étimo debiese tener Pl-, Fl-, Cl-, aunque en este caso la etimología que él mismo ha propuesto no tiene razón de ser. Pero si es voz aragonesa o vasco

${ }^{37}$ M. Alvar, Allas lingüístico y etnográfico de las Islas Canarias, Las Palmas, Ediciones del Excmo. Cabildo Insular, 1975-1978, 3 tomos.

38 Mapa 35.

39. Español Actual, 47 (1987)

40 Formas y estructuras del léxico agrícola andaluz. Interpretación y estudio de 200 mapas ling üisticos, Madrid, CSIC, 1975.

41 Ibídem, pág. 143.

42 A. Alcalá Venceslada, Vocabulario andaluz, Madrid, Gredos, 1980, reimpresión.

43 Fernández-Sevilla, op. cit., nota 1 a las págs. 143 y 144.

44 J. Corominas; J. A. Pascual, Diccionario Crítico Etimológico Castellano e Hispánico, Madrid, Gredos, 1980-1991, 6 tomos. 
navarra, teniendo en cuenta los antiguos casos aragoneses de $y$ - $>l l-$, cabría admitir un galicismo ${ }^{45}$.

Fernández-Sevilla ${ }^{46}$ pensando en los pueblos andaluces que conservan $l l$-, pensando en la variante lieta y observando los tallos de las patatas dice que dichos tallos al aflorar a la superficie cuando la tierra ha perdido humedad presionan contra la capa supeficial endurecida y salen al exterior doblados, «plegados», pues bien, pensando en ello, propone que lleta venga de un latín vulgar PLECTA 'enroscamiento, plegadura' con una tendencia a la simplificación del grupo-CT- o bien teniendo en cuenta una fuerza disimilatoria que impidió la formación de una segunda palatal ${ }^{47}$.

Nosotros nos vamos a fijar en las denominaciones que se emplean para la 'lleta'48: aguja, agujeta ${ }^{49}$, puyón ${ }^{50}$, aguijón $n^{51}$, punta ${ }^{52}$. Y, concretamente, en las provincias orientales de Andalucía puílla ${ }^{53}, p u b a^{54}$, aguijón $n^{55}$, etc. Con todo ello queremos indicar lo siguiente: la mayoría de las denominaciones empleadas para el 'tallo recién nacido' poseen la connotación de 'objeto punzante', también en la Andalucía oriental, y ello porque el brote primero cuando empuja para

45 S.v.lleta.Vid., además, V. García de Diego, Etimologías españolas, Valencia, Aguilar, 1964, págs. 103-104.

46 Op. cit.

47 Ibídem, $\$ 4.1$

48 ALEA, mapa citado.

49 Aguja (y vars. fonéts.: abuja, sobre todo), agujeta (y vars. fonéts.: abujeta, principalmente)aparecen de manera regular en las provincias occidentales de Andalucía, además de algunas localidades cordobesas y una del oeste de Granada - en contacto directo con la provincia de Málaga-. Indicamos con -eta cuando se trata de agujeta (y vars. fonéts.): $\mathrm{H} 100$ (-eta), 101 (id.), 102 (id.), 201 (id.), 202 (id.), 203 (id.), 300,301, 302, 400 (-eta), 401 (id.), 501 (id.), 601 (id.), 603 (id.); Se 100, 101 (-eta), 102, 200, 201, 300, 301 (-eta), 302 (id.), 310 (id.), 402 (id.), 500 (id.), 600 (id.), 601 (id.), 602 (id.), 603 (íd.); Ca 201 (-eta), 202 (id.), 203 (id.), 204 (id.), 205, 301 (-eta), 302 (íd.), 400, 500 (-eta), 600 (íd.); Ma 100 (-eta), 101 (íd.), 102 (íd.), 300, 301 (-eta), 303, 400, 401 (eta), 407 (íd), 500, 501, 502 (-eta), 503; Co 300 (-eta), 602 (-eta), 604 (-eta); Gr 507. Denominaciones derivadas de aguja, además de agujeta, son: agujilla (Ma 405), agujón ( $\mathrm{Gr} 408$ ) y agujones (Ca 101) que pueden ser aumentativos de aguja o bien variante fonética de aguijón con trueque de la vocal átona.

so Puyón se encuentra en localidades de Sevilla, un par de Huelva y otro par de Cádiz. Aunque el término figura en el mapa de una manera un tanto dispersa, sin embargo, podemos decir que es característico de las provincia occidentales. Así pues, puyón, concretamente, se halla en Se 305 , 308, 309, 400, 403, 501, 502, 503; H 504, 600; Ca 102, 601. Puyeando (H 402), a falta de una denominación concreta, puyar en Se 306 y Ca 100; apuyar en Se 308 y 309.

s1 Aguijón (y vars. fonéts.: a(gu)ijón, $(a)(g u) i j o ́ n)$ se halla en localidades dispersas: una al oeste de Huelva, otra en el SE de Sevilla, dos al sur de Córdoba y una en el SO de Granada: H 303 (pl.); Se 405; Co 605, 607; Gr 514.

52 Punta se localiza en un par de puntos de la provincia de Córdoba (Co 301, 600). De la misma familia etimológica son las respuestas apuntar (Se 406; Ma 402), apuntando (Ma 202; $\mathrm{Gr}$ 303) y puntanilla (H 602) que será un derivado de punta a través de puntón.
$53 \mathrm{Gr} 506$, aunque lleta es el 'brote de las plantas'.
$54 \mathrm{Gr} 203$.
s5 $\mathrm{Gr} 408$. 
nacer sale erguido ¿por qué, entonces, suponer que lleta (< PLECTA 'enroscamiento, plegadura') sea debido a que el tallo al salir a la luz lo haga en forma de arco cuando la realidad lingüística, en general, lo asimila a la idea de objeto punzante? Estamos ante una etimología por resolver.

Queremos concluir haciendo hincapié en el hecho de que la Academia tomó una desgraciada decisión el día que dejó de incluir la voz lleta. Que es verdad que hay muchos arcaísmos en los diccionarios que constituyen un peso muerto, que nadie conoce ni usa, pero que las cosas no se deben tomar a la ligera y no se puede poner y quitar voces en los diccionarios de una manera arbitraria.

Cfr. ALEANR, I, 49, LLETA

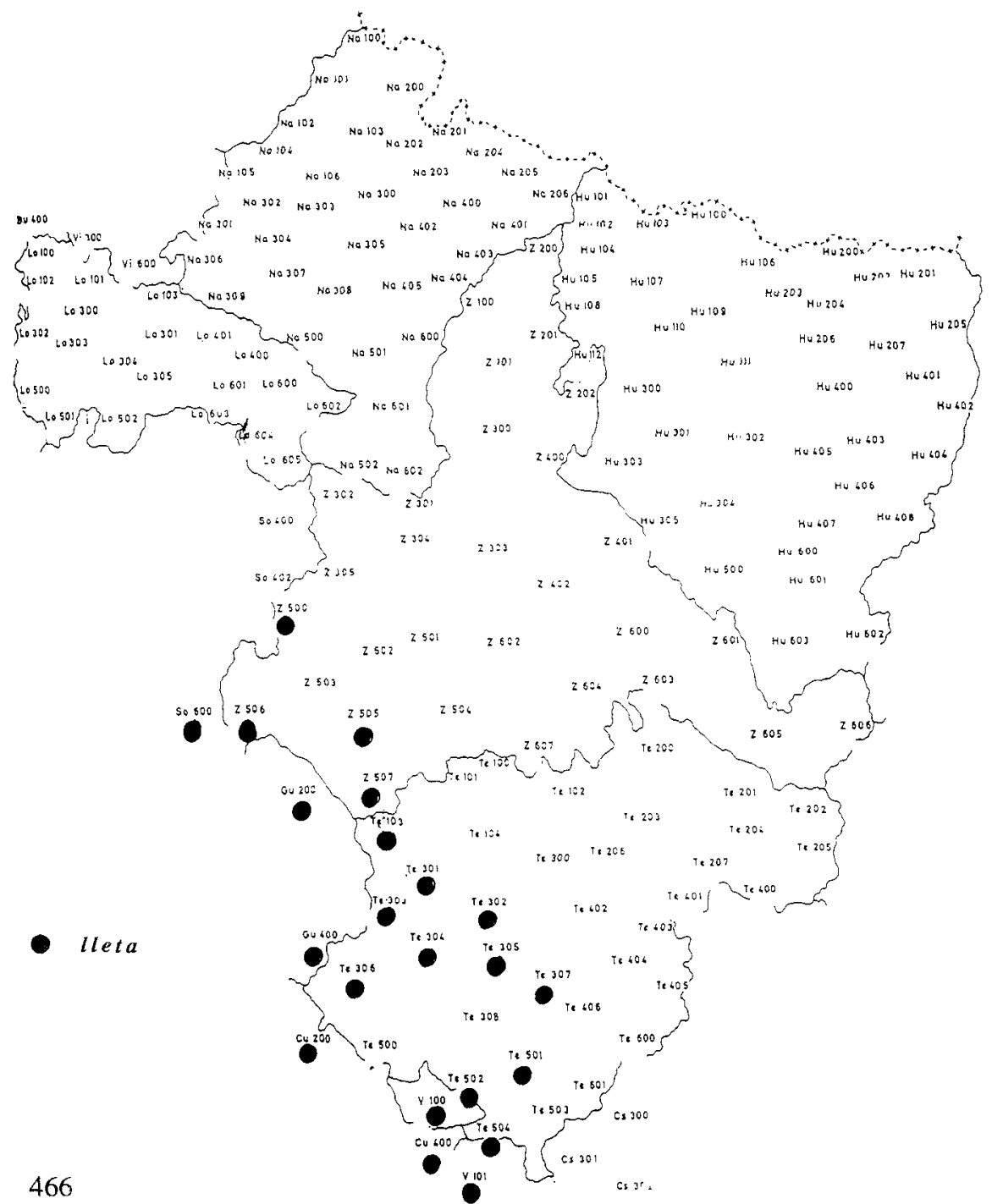




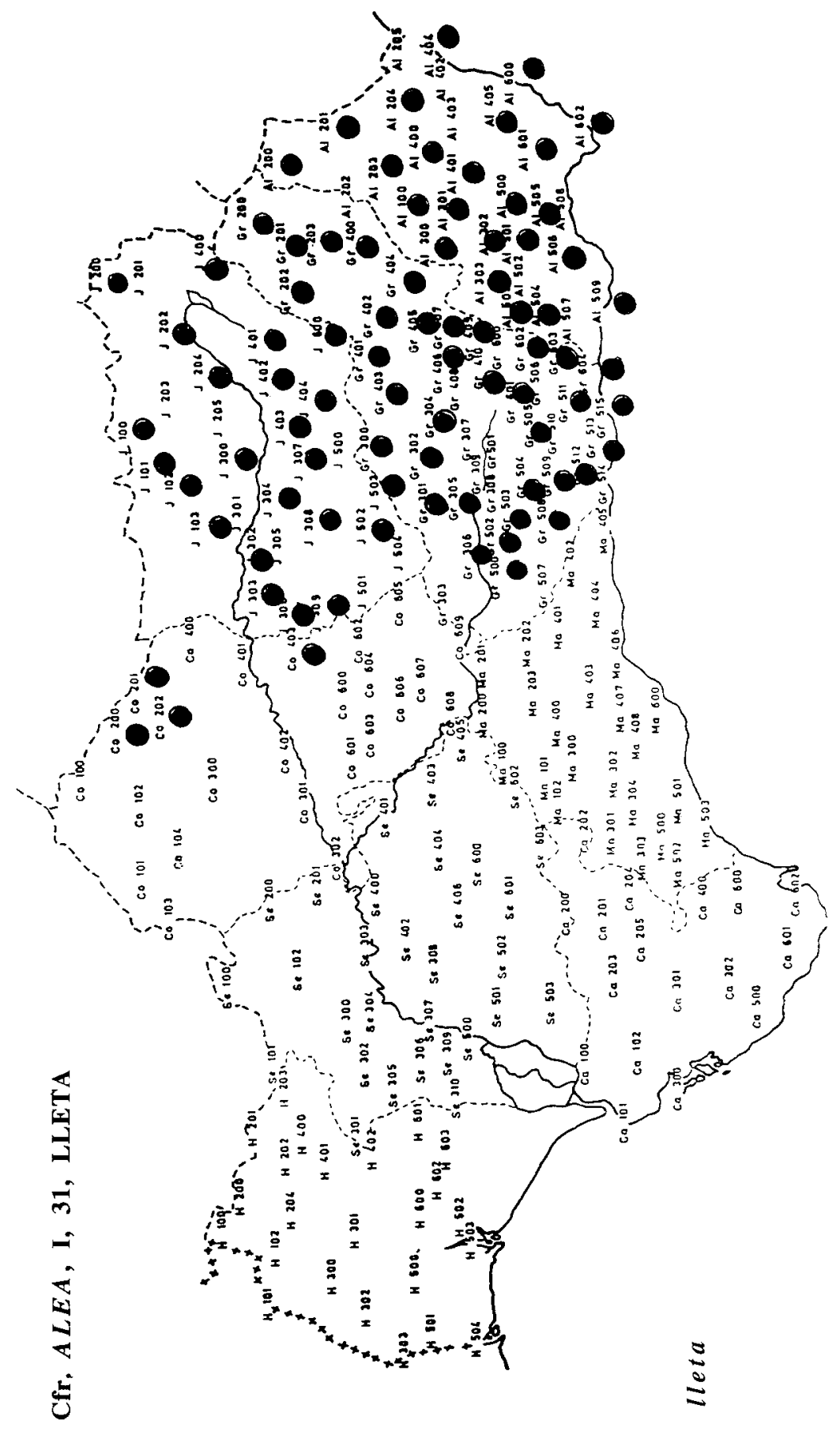

